\title{
Nominal Rigidity, Desired Markup Variations, and Real Exchange Rate Persistence
}

\author{
Hafedh Bouakez* \\ International Department, Bank of Canada
}

September 2002

\begin{abstract}
This paper develops and estimates a dynamic general-equilibrium sticky-price model that accounts for real exchange rate persistence. The key feature of the model is the dependence of the firm's desired markup on its relative price. Desired markup variations exacerbate the nominal rigidity that results from the exogenously imposed frictions in the goods market. The model is estimated by the maximum-likelihood method using Canadian and U.S. data. The estimated model successfully replicates the behaviour of the Canada-U.S. bilateral real exchange rate. In particular, the model closely matches the persistence found in the real exchange rate series. More importantly, this is achieved with a plausible duration of price contracts and a moderate convexity of the demand function.
\end{abstract}

JEL classification: F31, F41

Keywords: Desired markup variations, Persistence, Real exchange rate.

\footnotetext{
${ }^{*}$ I thank Jeannine Bailliu, Robert Lafrance, Larry Schembri, and seminar participants at the Bank of Canada for helpful comments and discussions. I also thank Qiao Zhang for excellent research assistance. Correspondence: International Department, Bank of Canada, 234 Wellington St., Ottawa, Canada K1A OG9. E-mail: hbouakez@bank-banque-canada.ca. The views expressed in this paper are mine. No responsibility for them should be attributed to the Bank of Canada.
} 


\section{Introduction}

In recent years, a new line of research on exchange rate determination, pioneered by the seminal work of Obstfeld and Rogoff (1995), has developed. The new approach examines exchange rate dynamics within dynamic general-equilibrium (DGE) sticky-price models. Examples of studies that use this approach include Betts and Devereux (2000), Chari, Kehoe, and McGrattan (2000a), Bergin and Feenstra (2001), and Kollmann (2001). In each of these studies, price stickiness is motivated through monopolistic competition in the goods market, while departures from the purchasing-power parity (PPP) are due to the failure of the law of one price (LOP) in traded goods. The latter feature arises from pricing-to-market behaviour by monopolistic firms that segment markets by country.

A primary objective of the literature on exchange rate determination is to account for the well-documented volatility and persistence of the real exchange rate. Figure 1 illustrates these stylized facts in the case of the Can $\$ / \mathrm{US} \$$ real exchange rate. The logged and Hodrick-Prescott (H-P) filtered Can\$/US\$ real exchange rate has a relative standard deviation of 2.09 with respect to Canadian real GDP, and a serial correlation of $0.86 .{ }^{1}$ Other bilateral real exchange rates with the U.S. dollar exhibit a similar degree of persistence and even higher volatility. ${ }^{2}$ Overall, the above-noted studies have been successful in generating high real exchange rate variability. In particular, using a careful parameterization of risk aversion, Chari, Kehoe, and McGrattan (2000a) closely replicate the volatility observed in the data. But unless they assume an unreasonable level of price rigidity (for example, via excessively long nominal contracts), standard DGE sticky-price models fail to match real exchange rate persistence. Additional features such as the incompleteness of the financial market and labour market frictions are shown by Chari, Kehoe, and McGrattan (2000a) to be quantitatively ineffective in generating more persistence. Furthermore, Bouakez (2002) finds that habit formation in consumer preferences is irrelevant to exchange rate persistence.

In this paper, I construct a DGE sticky-price model in the spirit of Obstfeld and Rogoff (1995). Departing from their model where the elasticity of demand is assumed to be constant, I allow this elasticity to be time-varying. More specifically, I consider a variety aggregator that yields an elasticity of demand that is increasing in relative price. This assumption may reflect search costs that cause a typical firm to lose more customers when

\footnotetext{
${ }^{1}$ These statistics are computed from quarterly data on the consumer price index (CPI)-based real exchange rate over the period 1975Q1-2001Q2.

${ }^{2}$ The average standard deviation (relative to that of output) of bilateral real exchange rates with the U.S. dollar for G-7 countries is about 4.8. See Bergin and Feenstra (2001).
} 
it raises its price than it gains when it reduces its price by the same amount. As Stiglitz (1979), Woglom (1982), and Ball and Romer (1990) point out, this information imperfection leads to kinked (or bent) demand curves. Ball and Romer (1990), Kimball (1995), Bergin and Feenstra (2000), and Rotemberg and Woodford (1999) show that a demand function with a time-varying elasticity exacerbates the real effects of monetary shocks. Intuitively, an elasticity of demand that is increasing in relative price means that the desired markup is decreasing in relative price. Because a monopolistic firm will lower its desired markup whenever it raises its relative price, the increase in the relative price will be smaller than it would be if the elasticity of demand was constant. Hence, allowing for desired markup variations leads to additional price stickiness beyond that resulting from the exogenously imposed frictions. A corollary is that a large degree of nominal rigidity may be rationalized with a reasonable exogenous length of nominal contracts.

In a related work, Bergin and Feenstra (2001) construct a model that incorporates translog preferences and materials inputs. Their results show that these two features generate endogenous real exchange rate persistence, but not to the extent actually observed in the data. This paper differs from Bergin and Feenstra's in two main respects. First, the demand function considered in this paper is general and can exhibit any desirable degree of curvature. In contrast, the translog preferences that Bergin and Feenstra assume imply a limited curvature of the resulting demand function. Second, and more importantly, Bergin and Feenstra use calibration to assess the relevance of the key elements of their model. I, instead, derive an empirical model and obtain econometric estimates of the structural parameters. To the best of my knowledge, with the exception of a very recent paper by Bergin (2002), no previous studies have attempted to estimate DGE sticky-price models of exchange rate determination. ${ }^{3}$

The model is estimated via maximum likelihood (ML) using data on the Can\$/US\$ real exchange rate, the inflation differential between Canada and the United States, and the relative real money stock between the two countries. The results show that the model performs remarkably well in explaining in-sample real exchange rate dynamics. In particular, the model predicts the same autocorrelation found in the Can $\$ / \mathrm{US} \$$ real exchange rate series. Moreover, I find that, with a constant desired markup, prices have to be fixed for

\footnotetext{
${ }^{3}$ Apart from using related estimation methodologies, this paper and the one by Bergin (2002) are distinctly different. In particular, Bergin (2002) estimates a small open economy model with price and wage rigidities and focuses on testing the theoretical model by comparing its likelihood with that of an unrestricted counterpart. In this study, I estimate a two-country sticky-price model with the aim of explaining real exchange rate persistence.
} 
18 quarters on average for the model to match real exchange rate persistence. If, however, one allows markups to vary by a reasonable amount, then the model generates the required persistence with a plausible duration of price contracts. Variance decomposition indicates that monetary shocks explain more than 40 per cent of real exchange rate variability in the short run and roughly 50 per cent of its unconditional variance.

The rest of this paper is organized as follows. Section 2 presents the theoretical model. Section 3 provides some intuition for the role of desired markup variations. Section 4 describes the estimation methodology and the data. Section 5 reports the empirical results and performs a robustness analysis. Section 6 concludes.

\section{The Model}

The model consists of two countries, each characterized by (i) a representative infinitely lived household, (ii) a representative final-good producer, (iii) a continuum of intermediate-good producers indexed by $i \in[0,1]$, and (iv) a government. A fraction $n$ (respectively, $1-n$ ) of intermediate-good producers are located in the home (foreign) country. Intermediate goods are differentiated and are used to produce the final good in both countries. The final good is used exclusively for consumption and is not tradable between the two countries.

\section{$2.1 \quad$ Households}

The representative household in the home country has the following lifetime utility function:

$$
U_{t}=E_{t} \sum_{s=t}^{\infty} \beta^{s-t} u\left(c_{s}, m_{s}\right),
$$

where $E_{t}$ denotes the mathematical expectation conditional on the information available up to and including period $t, \beta$ is the subjective discount factor $(0<\beta<1)$, and $u$ is the instantaneous utility function. Households derive utility from consumption $(c)$ and from holding real money balances $(m){ }^{4}$ The instantaneous utility function is assumed to be

$$
u\left(c_{t}, m_{t}\right)=v\left(c_{t}\right)+\frac{\gamma}{1-\eta} m_{t}^{1-\eta}
$$

\footnotetext{
${ }^{4}$ I assume that households do not derive utility from leisure. Hence, labour supply is perfectly inelastic in this model. I argue further (section 2.5) that this assumption is completely innocuous and does not affect the results of this study.
} 
where the function $v$ satisfies $v^{\prime}(c)>0$ and $v^{\prime \prime}(c)<0, m_{t}=M_{t} / P_{t}, M_{t}$ is the nominal money stock, $P_{t}$ is the aggregate price index, and $\gamma$ is a positive parameter. ${ }^{5}$

Foreign money is not held by home-country residents and vice versa. Both countries' residents, however, can hold interest-bearing, one-period nominal bonds denominated in domestic currency. The nominal interest rate on bonds due at time $t+1$ is denoted by $i_{t}$. The household's resources at the beginning of period $t$ consist of money holdings set aside in period $t-1$ and the gross return on bonds purchased at time $t-1$. The household then receives a lump-sum transfer from the government. Next, the bonds market opens, allowing the household to purchase new nominal bonds. During period $t$, the household sells $l_{t}(i)$ units of labour to each intermediate-good producer $i \in[0, n]$ at the nominal wage, $W_{t}$. It also receives dividends $D_{t}(i)$ from each intermediate-good producer $i \in[0, n]$. The household allocates some of its income to consumption and carries the remaining units of money into period $t+1$.

The representative household's budget constraint, expressed in real terms, is

$$
c_{t}+b_{t}+m_{t} \leq\left(1+i_{t-1}\right) b_{t-1} / \pi_{t}+m_{t-1} / \pi_{t}+w_{t} \bar{l}+d_{t}+\tau_{t}
$$

where $b_{t}=B_{t} / P_{t}, B_{t}$ are nominal bond holdings, $\pi_{t}$ is the gross inflation rate between $t-1$ and $t, w_{t}$ is the real wage, $\bar{l}=\int_{0}^{n} l_{t}(i) d i$ is the household's total endowment of time, $d_{t}=D_{t} / P_{t}, D_{t}=\int_{0}^{n} D_{t}(i) d i$ are total dividends, and $\tau_{t}$ is a real lump-sum transfer.

The representative household in the foreign country has the following budget constraint:

$$
c_{t}^{*}+b_{t}^{*} / e_{t}+m_{t}^{*}=\left(1+i_{t-1}\right)\left(b_{t-1}^{*} / e_{t}\right) / \pi_{t}^{*}+m_{t-1}^{*} / \pi_{t}^{*}+w_{t}^{*} \bar{l}^{*}+d_{t}^{*}+\tau_{t}^{*},
$$

where the asterisk denotes variables in the foreign country and $e_{t}$ is the nominal exchange rate, defined as the price of one unit of the foreign currency in terms of the home currency.

I assume that financial markets are complete, meaning that there exists a complete set of state-contingent Arrow-Debreu bonds that allow households in both countries to pool risks perfectly. Technically, under this assumption, the maximization problems of the domestic and foreign representative households are equivalent to a social planner's problem of maximizing a weighted sum of the utilities of both households subject to the world resources constraint expressed in domestic currency. Because households are identical within each country, the weight attached to the utility of each representative household corresponds to

\footnotetext{
${ }^{5}$ The assumption of separability between consumption and money in the utility function is not crucial and could easily be relaxed.
} 
the population size in its country of origin. ${ }^{6}$ The first-order necessary conditions associated with the optimal choice of $c_{t}, c_{t}^{*}, b_{t}, b_{t}^{*}, m_{t}$, and $m_{t}^{*}$ for this problem are

$$
\begin{aligned}
\lambda_{t} & =v^{\prime}\left(c_{t}\right), \\
\lambda_{t} q_{t} & =v^{\prime}\left(c_{t}^{*}\right), \\
\lambda_{t} & =\beta\left(1+i_{t}\right) E_{t}\left(\lambda_{t+1} / \pi_{t+1}\right), \\
\gamma m_{t}^{-\eta} & =\lambda_{t}-\beta E_{t}\left(\lambda_{t+1} / \pi_{t+1}\right), \\
\gamma m_{t}^{*-\eta} & =\lambda_{t} q_{t}-\beta E_{t}\left(\lambda_{t+1} q_{t+1} / \pi_{t+1}^{*}\right),
\end{aligned}
$$

where $\lambda_{t}$ is the Lagrange multiplier associated with the combined budget constraint and $q_{t}=e_{t} P_{t}^{*} / P_{t}$ is the real exchange rate. ${ }^{7}$ Equations (3) and (4) imply the following risksharing condition:

$$
v^{\prime}\left(c_{t}^{*}\right) / v^{\prime}\left(c_{t}\right)=q_{t},
$$

which states that, to the extent that the PPP holds, domestic and foreign households will enjoy the same level of consumption. Equation (5) is the standard Euler equation that prices nominal bonds. Equations (6) and (7) describe the optimal trade-off between consumption and money holdings. Equations (5) and (6) lead to the following money-demand equation:

$$
\gamma m_{t}^{-\eta}=\lambda_{t}\left(\frac{i_{t}}{1+i_{t}}\right)
$$

where the parameter $\eta$ can be interpreted as the inverse of the interest elasticity of money demand.

\subsection{The final-good producer}

Final-good producers are perfectly competitive. They use the differentiated intermediate goods from both countries to produce a single, country-specific perishable commodity. I follow Kimball (1995) in assuming that the technology for producing the domestic final good is given implicitly by

$$
1=\int_{0}^{n} \psi\left(y_{h t}(i) / y_{t}\right) d i+\int_{n}^{1} \psi\left(y_{f t}(i) / y_{t}\right) d i
$$

where $y_{t}$ is the aggregate output, $y_{h t}(i)$ (respectively, $y_{f t}(i)$ ) is the input of intermediate good $i$ produced in the home (foreign) country, and the function $\psi$ satisfies $\psi(1)=1, \psi^{\prime}(x)>$

\footnotetext{
${ }^{6}$ This weighting ignores initial wealth differences between the two countries.

${ }^{7}$ Differentiating the Lagrangian with respect to $b_{t}^{*}$ leads to the same first-order condition as equation (5).
} 
0 and $\psi^{\prime \prime}(x)<0$, for all $x \geq 0$. It is assumed that exports are invoiced in the currency of the importing country. This assumption, often called local currency pricing (LCP), was introduced by Betts and Devereux (1996, 2000) into Obstfeld and Rogoff's (1995) model to characterize pricing-to-market behaviour by monopolistic firms. Pricing-to-market is the ability of a monopoly to set different prices in the home and foreign countries by somehow segmenting the market. Typically, this price discrimination leads to the violation the LOP among traded goods, and ultimately to a departure from the PPP. It is clear, though, that such behaviour is possible only if there are economic and/or institutional constraints that prevent consumers from taking advantage of international arbitrage opportunities in the goods market. Empirically, studies by Knetter (1989, 1993), Engel (1993), and Engel and Rogers (1996) seem to provide strong evidence in favour of pricing-to-market, as departures from PPP were found to reflect mainly the failure of the LOP between traded goods, rather than the presence of non-traded goods. Under the assumption of LCP, the final-good producer solves the following problem:

$$
\underset{\left\{y_{h t}(i), y_{f t}(i)\right\}}{\operatorname{Min}} \int_{0}^{n} P_{h t}(i) y_{h t}(i) d i+\int_{n}^{1} P_{f t}(i) y_{f t}(i) d i,
$$

subject to (10), where $P_{h t}(i)$ (respectively, $P_{f t}(i)$ ) is the price of intermediate-good $i$ produced in the home (foreign) country. The solution of this problem yields the input demand of $\operatorname{good} i$ :

$$
y_{j t}(i)=y_{t} \psi^{\prime-1}\left(\psi^{\prime}(1) P_{j t}(i) / P_{t}\right),
$$

where $j=h$ for $i \in[0, n]$ and $j=f$ for $i \in] n, 1]$. $P_{t}$ is the aggregate price index given implicitly by

$$
P_{t}=\int_{0}^{n} P_{h t}(i) \psi^{\prime-1}\left(\psi^{\prime}(1) P_{h t}(i) / P_{t}\right) d i+\int_{n}^{1} P_{f t}(i) \psi^{\prime-1}\left(\psi^{\prime}(1) P_{f t}(i) / P_{t}\right) d i .
$$

Let $P_{h t}$ and $P_{f t}$ denote, respectively, the price indexes of home and foreign intermediate goods sold in the home country. ${ }^{8}$ Hence, the aggregate price index can be written as

$$
P_{t}=n P_{h t}+(1-n) P_{f t} .
$$

The problem of the representative foreign final-good producer is described in an analogous manner.

\footnotetext{
${ }^{8}$ More precisely, $P_{h t}$ and $P_{f t}$ are defined as follows:

$P_{h t} \equiv \frac{1}{n} \int_{0}^{n} P_{h t}(i) \psi^{\prime-1}\left(\psi^{\prime}(1) P_{h t}(i) / P_{t}\right) d i$ and $P_{f t} \equiv \frac{1}{1-n} \int_{n}^{1} P_{f t}(i) \psi^{\prime-1}\left(\psi^{\prime}(1) P_{f t}(i) / P_{t}\right) d i$
} 


\subsection{The intermediate-good producer}

The representative firm $i$ in the home country produces its differentiated good using the simple technology

$$
y_{t}(i) \equiv y_{h t}(i)+y_{h t}^{*}(i)=h_{t}(i)
$$

where $h_{t}(i)$ denotes labour input..$^{9}$ Intermediate-good producers are monopolistically competitive. Each firm faces a downward-sloping demand curve for its differentiated good in each country. Firm $i$ chooses its (nominal) prices, $P_{h}(i)$ and $P_{h}^{*}(i)$, taking as given the aggregate demand and the price level in each country. Nominal prices are assumed to be sticky. Price stickiness is modeled à la Calvo (1983). That is, each period, some firms are randomly selected to set new prices for the home and foreign markets. The probability of being selected in any particular period is constant and is equal to $1-\varphi$.

Let us denote by $\tilde{P}_{h t}$ and $\tilde{P}_{h t}^{*}$ the optimal prices set by a typical firm at period $t$ in the home and foreign countries, respectively. It is not necessary to index $\tilde{P}_{h t}$ and $\tilde{P}_{h t}^{*}$ by firm, because all of the firms that change their prices at a given time choose the same price (see Woodford 1996). The total domestic and foreign demands facing this firm at time $s$ for $s \geq t$ are $\tilde{y}_{h s}=y_{s} \psi^{\prime-1}\left(\psi^{\prime}(1) \tilde{P}_{h t} / P_{s}\right)$ and $\tilde{y}_{h s}^{*}=y_{s}^{*} \psi^{\prime-1}\left(\psi^{\prime}(1) \tilde{P}_{h t}^{*} / P_{s}^{*}\right)$, respectively. The probability that $\tilde{P}_{h t}$ and $\tilde{P}_{h t}^{*}$ "survive" at least until period $s$, for $s \geq t$, is $\varphi^{s-t}$. Thus, the intermediate-good producer chooses $\tilde{P}_{h t}$ and $\tilde{P}_{h t}^{*}$ to maximize

$$
E_{t} \sum_{s=t}^{\infty}(\varphi \beta)^{s-t} \Lambda_{t, s}\left[\tilde{P}_{h t} \tilde{y}_{h s}+e_{s} \tilde{P}_{h t}^{*} \tilde{y}_{h s}^{*}-W_{s}\left(\tilde{y}_{h s}+\tilde{y}_{h s}^{*}\right)\right]
$$

where $\Lambda_{t, s}$ is the marginal utility of a dollar earned at time $s$ relative to its marginal utility at time $t$. First-order conditions for this problem are

$$
\begin{aligned}
\tilde{P}_{h t} & =\frac{E_{t} \sum_{s=t}^{\infty}(\varphi \beta)^{s-t} \Lambda_{t, s} \theta_{s}\left(\tilde{y}_{h s} / y_{s}\right) W_{s} \tilde{y}_{h s}}{E_{t} \sum_{s=t}^{\infty}(\varphi \beta)^{s-t} \Lambda_{t, s}\left(\theta_{s}\left(\tilde{y}_{h s} / y_{s}\right)-1\right) \tilde{y}_{h s}} \\
\tilde{P}_{h t}^{*} & =\frac{E_{t} \sum_{s=t}^{\infty}(\varphi \beta)^{s-t} \theta_{s}\left(\tilde{y}_{h s}^{*} / y_{s}^{*}\right) W_{s} \tilde{y}_{h s}^{*}}{E_{t} \sum_{s=t}^{\infty}(\varphi \beta)^{s-t}\left(\theta_{s}\left(\tilde{y}_{h s}^{*} / y_{s}^{*}\right)-1\right) e_{s} \tilde{y}_{h s}^{*}}
\end{aligned}
$$

where $\theta($.$) is the elasticity of demand given by: \theta(x)=-\frac{\psi^{\prime}(x)}{x \psi^{\prime \prime}(x)} \cdot{ }^{10}$

Note that, in the flexible-price case $(\varphi=0)$, the right-hand sides of equations (13) and (14) collapse to $\frac{\theta}{\theta-1}$, where $\theta \equiv \theta(1)$. That is, the optimal price in each country is set as a

\footnotetext{
${ }^{9}$ Labour market clearing requires that $\int_{0}^{n} h_{t}(i) d i=n \bar{l}$.

${ }^{10}$ To see this, note that from $(11)$ we have $\frac{1}{\theta(y(i) / y)} \equiv-\frac{\partial \ln P(i)}{\partial y(i)} y(i)=-\frac{(y(i) / y) \psi^{\prime \prime}(y(i) / y)}{\psi^{\prime}(y(i) / y)}$.
} 
constant markup over the nominal marginal cost (the nominal wage, in this model). When prices are sticky $(0<\varphi \leq 1)$, however, the markup becomes dynamic, for two reasons. First, since the nominal wage is perfectly flexible while prices adjust only sluggishly, the markup unavoidably deviates from the flexible-price-equilibrium value of $\frac{\theta}{\theta-1}$. Second, price stickiness implies that the price set by a monopolistic firm in a given country at a given time is different from the aggregate price level in that country at that time. This means that the relative price of that firm is different from unity. Because the elasticity of demand depends on the firm's market share, or, equivalently, on its relative price, the desired markup, defined as $\nu(x) \equiv \frac{\theta(x)}{\theta(x)-1}$, varies whenever the economy deviates from the flexible-price equilibrium. Clearly, this second source of markup variations (that is, variations in the desired markup) cannot arise in a model in which the elasticity of demand is constant.

Although it is fairly easy to construct a variety aggregator that leads to any desirable dependance of the elasticity of demand (and consequently the desired markup) on the firm's relative output (see Kimball 1995), I need not specify a functional form for $\psi$, since I will solve the model up to a first-order approximation. Instead, I need only specify the elasticity of the desired markup with respect to the firm's market share. This elasticity is assumed to be constant and is denoted by $\xi(\xi>0)$.

Assuming that price changes are independent across firms, the law of large numbers implies that $1-\varphi$ is also the proportion of firms that set a new price each period. The proportion of firms that set a new price at time $s$ and have not changed it as of time $t$ (for $s \leq t)$ is given by the probability that a time- $s$ price is still in effect in period $t$. It is easy to show that this probability is $\varphi^{t-s}(1-\varphi)$. It follows that $P_{h t}$ and $P_{h t}^{*}$ can be written, respectively, as

$$
\begin{aligned}
& P_{h t}=(1-\varphi) \sum_{s=-\infty}^{t} \varphi^{t-s} \tilde{P}_{h s} \psi^{\prime-1}\left(\psi^{\prime}(1) \tilde{P}_{h s} / P_{t}\right) \\
& P_{h t}^{*}=(1-\varphi) \sum_{s=-\infty}^{t} \varphi^{t-s} \tilde{P}_{h s}^{*} \psi^{\prime-1}\left(\psi^{\prime}(1) \tilde{P}_{h s}^{*} / P_{t}^{*}\right) .
\end{aligned}
$$

\subsection{The government}

The government represents both the fiscal and monetary authorities in each country. There is no government spending or investment. Each period, the government makes lump-sum transfers to households. Transfers are financed by printing additional money in each period. 
Thus, the government budget constraint in the home country is

$$
\tau_{t}=m_{t}-m_{t-1} / \pi_{t}
$$

Money is supplied exogenously by the government according to $M_{t}=\mu_{t} M_{t-1}$, where $\mu_{t}$ is the gross rate of money growth. In real terms, this process implies

$$
m_{t} \pi_{t}=\mu_{t} m_{t-1}
$$

The rate of money growth, $\mu_{t}$, is assumed to follow a first-order autoregressive process given by

$$
\ln \mu_{t}=\left(1-\rho^{\mu}\right) \ln \mu+\rho^{\mu} \ln \mu_{t-1}+\epsilon_{\mu, t},
$$

where $\rho^{\mu}$ is strictly bounded between -1 and $1, \mu$ is the rate of money growth at the steady state, and $\epsilon_{\mu, t}$ is a normally distributed zero-mean disturbance with variance $\sigma_{\epsilon_{\mu}}^{2}$. Moneygrowth shocks are assumed to be non-correlated across countries. On the other hand, the first-order autocorrelation, $\rho^{\mu}$, is assumed to be the same for both countries.

\subsection{The log-linearized model}

Since the model cannot be solved analytically, I follow the usual strategy of considering an approximate solution in the neighbourhood of the steady state. I do so by log-linearizing the equilibrium conditions around a zero-shock initial steady state in which all variables are constant. The steady state corresponds to a symmetric flexible-price equilibrium. From the log-linearized version of the model, it is easy to show that the real exchange rate (expressed as a percentage deviation from its steady-state value) is fully determined by the following four-equation system (see Appendix A for the derivation):

$$
\begin{aligned}
\hat{\mu}_{t}^{d} & =\rho^{\mu} \hat{\mu}_{t-1}^{d}+\epsilon_{\mu, t}^{d}, \\
\hat{m}_{t}^{d} & =\hat{m}_{t-1}^{d}-\hat{\pi}_{t}^{d}+\hat{\mu}_{t}^{d}, \\
E_{t} \hat{\pi}_{t+1}^{d} & =\frac{1}{\beta} \hat{\pi}_{t}^{d}-\kappa \hat{q}_{t}, \\
E_{t} \hat{q}_{t+1} & =\frac{1}{\beta} \hat{q}_{t}-E_{t} \hat{\pi}_{t+1}^{d}-\frac{\eta(1-\beta)}{\beta} \hat{m}_{t}^{d},
\end{aligned}
$$

where the circumflex denotes the percentage deviation of a variable from its steady-state value $\left[\hat{x}_{t}=\left(x_{t}-x\right) / x\right]$, the superscript $d$ denotes the difference between home and foreign values of a given variable $\left[x_{t}^{d}=\left(x_{t}-x_{t}^{*}\right)\right]$, and $\kappa \equiv \frac{(1-\varphi)(1-\varphi \beta)}{\varphi \beta(1+\theta \xi)}$ is a positive parameter. 
Equations (20) and (21) have straightforward interpretations: they are, respectively, the stochastic process for money growth and the money-supply equation, expressed in country differences. Equation (22) extends the standard closed-economy neo-Keynesian Phillips curve to a two-country framework. This equation, which might be interpreted as an international Phillips curve, stems from the combination of both countries' Phillips curves (equations (A.12) and (A.13)). Owing to openness, these curves depend not only on the domestic real marginal cost, as in a closed-economy set-up, but also on the foreign real marginal cost and the real exchange rate. ${ }^{11}$ Because the domestic and foreign real marginal costs enter identically both countries' Phillips curves, these variables cancel each other out when the foreign Phillips curve is subtracted from the domestic one (or vice versa). The resulting equation is one that links the inflation differential to the real exchange rate. From the viewpoint of estimating the structural parameters $\beta$ and $\kappa$ within a single-equation model, equation (22) might be easier to estimate than the closed-economy Phillips curve, because a measure of the real exchange rate is more easily obtained than one for the real marginal cost. Finally, equation (23) ensues from the combination of money-demand equations in the two countries. ${ }^{12}$ Note that equations (20)-(23) hold regardless of the degree of elasticity of labour supply by the households, which justifies our simplifying assumption of an inelastic labour supply. The model is also robust to the specification of the technology and the inputs used in the production of the intermediate goods. For example, allowing for capital accumulation in the model will not alter equations (20)-(23) in any way.

The log-linearized model (20)-(23) can be written as

$$
\left[\begin{array}{c}
\mathbf{x}_{t+1} \\
E_{t} \mathbf{p}_{t+1}
\end{array}\right]=\left[\begin{array}{ll}
\mathbf{a}_{11} & \mathbf{a}_{12} \\
\mathbf{a}_{21} & \mathbf{a}_{22}
\end{array}\right]\left[\begin{array}{c}
\mathbf{x}_{t} \\
\mathbf{p}_{t}
\end{array}\right]+\left[\begin{array}{l}
1 \\
0
\end{array}\right] \otimes \epsilon_{t+1}
$$

where $\mathbf{x}_{t}=\left(\hat{\mu}_{t}^{d}, \hat{m}_{t-1}^{d}\right)^{\prime}$ is a $2 \times 1$ vector that contains the state variables in the system, $\mathbf{p}_{t}=\left(\hat{\pi}_{t}^{d}, \hat{q}_{t}\right)^{\prime}$ is a $2 \times 1$ vector that contains the forward-looking variables, $\epsilon_{t}=\left(\epsilon_{\mu, t}^{d}, 0\right)^{\prime}$ is a $2 \times 1$ vector, and $\mathbf{a}_{i j} i, j=1,2$ are $2 \times 2$ matrices whose elements are combinations of structural parameters. The Blanchard-Kahn (1980) method can be applied to (24) to obtain

$$
\begin{aligned}
\mathbf{x}_{t+1} & =\mathbf{F} \mathbf{x}_{t}+\epsilon_{t+1}, \\
\mathbf{p}_{t} & =\mathbf{Q} \mathbf{x}_{t}
\end{aligned}
$$

\footnotetext{
${ }^{11}$ See Razin and Yuen (2001) and Galí and Monacelli (2002) for a generalization of the neo-Keynesian Phillips curve in the context of an open economy.

${ }^{12}$ The key assumption in deriving equation (23) is the completeness of financial markets.
} 
where the matrices $\mathbf{F}$ and $\mathbf{Q}$ are $2 \times 2$ matrices that contain combinations of the elements of $\mathbf{a}_{i j}, i, j=1,2$.

\section{Some Intuition}

In this section, I provide some intuition about the role of desired markup variations and how they affect real exchange rate dynamics. For this purpose, I use impulse-response analysis to show how the response of the real exchange rate to a monetary shock depends on the parameter $\xi$. The first step is to assign plausible values to the remaining structural parameters. Hence, I set $\beta$ to 0.99 so that the annual real interest rate in the steady state is about 4 per cent. The probability of not changing price in a given quarter, $\varphi$, is set to 0.75 . This parameterization of $\varphi$ is consistent with Taylor's (1999) conclusion, reached after he surveyed the empirical literature on price-setting, that prices are fixed for approximately four quarters on average in the United States. Following Kimball (1995), and in conformity with the empirical results of Basu and Fernald (1994), I choose $\theta=11 .^{13}$ I set $\eta$ to 10 , which means that the interest elasticity of money demand is equal to 0.1 , as estimated by Ireland (2001) and Christiano, Eichenbaum, and Evans (2001). This elasticity, however, has not been decisively estimated by previous empirical studies, as econometric estimates range from 0.05 in Mankiw and Summers (1986) to 0.39 in Chari, Kehoe, and McGrattan (2000b). Finally, the autocorrelation coefficient of the relative monetary shock, $\rho^{\mu}$, is calibrated to 0.5 .

The impulse-response functions generated by the model in response to a 1 per cent relative money-growth shock are depicted in Figure 2. These responses are computed for different values of $\xi$, ranging from 0 to 5 . Figure 2 shows that, regardless of the magnitude of $\xi$, a positive money-growth shock triggers initial jumps in the inflation differential, real exchange rate, and relative real money stock. All three variables then return gradually to their steady-state values. As $\xi$ increases, however, the dynamic paths of the variables become more persistent, as the initial effects of the shock take longer to die out. In addition, on impact, the real exchange rate depreciates more as $\xi$ rises. Hence, allowing the desired markup to depend on the relative price seems to magnify the volatility and the persistence of the real exchange rate. To understand this result, it is useful to rewrite equation (22) as

$$
\hat{\pi}_{t}^{d}=\beta E_{t} \hat{\pi}_{t+1}^{d}+\beta \kappa \hat{q}_{t} .
$$

\footnotetext{
${ }^{13}$ Basu and Fernald (1994) report markup estimates of about 10 per cent for U.S. data. This value implies that the elasticity of demand in the steady state $(\theta)$ is equal to $\frac{10}{10-1}=11$.
} 
Because the parameter $\kappa$ is decreasing in $\xi$, $\hat{\pi}_{t}^{d}$ is lower the higher is $\xi$, for any given values of $E_{t} \hat{\pi}_{t+1}^{d}, \hat{q}_{t}$, and the parameters $\beta, \varphi$, and $\theta$. That is, the inflation differential jumps less (following a shock) as $\xi$ increases, ceteris paribus. As expected, the top panel of Figure 2 clearly shows that rising $\xi$ dampens the initial effect of the relative monetary shock on the inflation differential. To obtain the intuition for this result, it is instructive to examine the optimal pricing decisions that characterize the intermediate-good producers in the two countries (equations (A.4), (A.6), (A.7), and (A.8)). In each of these equations, the optimal relative price of a typical monopolistic firm is a decreasing function of $\xi$. Because the elasticity of demand is an increasing function of the firm's relative price (or, equivalently, the desired markup is an increasing function of the firm's market share), the re-optimizing firm is reluctant to charge a higher price following a positive monetary shock. ${ }^{14}$ Since all monopolistic firms have less incentive to change prices by much with $\xi>0$, the jumps in the aggregate price level are smaller and inflation is more inertial than in the case where $\xi=0$. Thus, desired markup variations act as an additional source of price rigidity and lead to persistent effects of monetary shocks on real variables, including the real exchange rate. Note, however, that money neutrality still holds when prices are perfectly flexible, since the desired markup remains constant in this case. In other words, desired markup variations amplify the effects of monetary shocks only to the extent that prices are sticky. On the other hand, a given degree of price stickiness may be rationalized with a lower value of the probability of not changing price $\varphi$, once one allows for desired markup variations.

To gain further insight into how the interaction of price rigidity and desired markup variations increases real exchange rate persistence, I compute the autocorrelation of the simulated real exchange rate series, $\varrho$, for different combinations of $\varphi$ and $\xi$. The resulting three-dimensional graph is plotted in Figure 3. This figure shows that $\varrho$ increases nonmonotonically with $\varphi$ and $\xi$. In particular, holding $\varphi$ constant, the gain in persistence from increasing $\xi$ is larger when starting from relatively low values of this parameter. More importantly, Figure 3 suggests that, at least theoretically, it is possible to replicate any value of $\varrho$ with an appropriate choice of $\varphi$ and $\xi$. This is precisely what is illustrated in Figure 4, which depicts the combinations of $\varphi$ and $\xi$ that lead to the same value of $\varrho$. The resulting iso-persistence curves suggest that, eventually, the observed persistence of the real exchange rate can be replicated with reasonable values of $\varphi$, provided that $\xi$ is sufficiently greater than zero.

\footnotetext{
${ }^{14}$ See Rotemberg and Woodford (1999) for further discussion.
} 


\section{Estimation Methodology and Data}

The Blanchard-Kahn solution $(25,26)$ can be rewritten to collect the state variables into a transition equation and the observable variables into a measurement equation. This yields the following state-space representation of the model:

$$
\begin{aligned}
\mathbf{x}_{t+1} & =\mathbf{F x}_{t}+\epsilon_{t+1}, \\
\mathbf{y}_{t} & =\mathbf{H x}_{t},
\end{aligned}
$$

where $\mathbf{y}_{t}=\left(\hat{\pi}_{t}^{d}, \hat{q}_{t}, \hat{m}_{t}^{d}\right)^{\prime}$ and $\mathbf{H}$ is a $3 \times 2$ matrix that includes combinations of the structural parameters. Provided that there are at least as many shocks as observable variables, dynamic systems like $(27,28)$ can be estimated by ML using the Kalman filter to evaluate the likelihood function. The ML estimator obtained in this case would be consistent and asymptotically efficient. If the number of variables in the measurement equation exceeds the number of shocks, however, as it does here, the variance-covariance matrix of the residuals will be singular. One approach to circumvent this problem is to add measurement (nonstructural) errors to the variables in the observation equation. Studies using this strategy include Altug (1989), McGrattan (1994), McGrattan, Rogerson, and Wright (1997) and Ireland (1999). Following these studies, I assume that the measurement errors are serially correlated. Hence, the model becomes

$$
\begin{aligned}
\mathbf{x}_{t+1} & =\mathbf{F x}_{t}+\epsilon_{t+1}, \\
\mathbf{y}_{t} & =\mathbf{H} \mathbf{x}_{t}+\mathbf{u}_{t}, \\
\mathbf{u}_{t+1} & =\mathbf{D} \mathbf{u}_{t}+\mathbf{e}_{t+1}
\end{aligned}
$$

where $\mathbf{u}_{t}=\left(u_{\pi, t}, u_{q, t}, u_{m, t}\right)^{\prime}, \mathbf{D}$ is a $3 \times 3$ diagonal matrix with elements $\rho^{\pi}, \rho^{q}$, and $\rho^{m}$ (which are strictly bounded between -1 and 1 ), and the innovations $\mathbf{e}_{t}=\left(e_{\pi, t}, e_{q, t}, e_{m, t}\right)^{\prime}$ are assumed to be normally distributed with a zero mean and the following variance-covariance matrix:

$$
\mathbf{V}=\operatorname{Var}\left(\mathbf{e}_{t} \mathbf{e}_{t}^{\prime}\right)=\left[\begin{array}{ccc}
\sigma_{e_{\pi}}^{2} & 0 & 0 \\
0 & \sigma_{e_{q}}^{2} & 0 \\
0 & 0 & \sigma_{e_{m}}^{2}
\end{array}\right]
$$

The model is estimated using Canadian and U.S. quarterly data ranging from 1975Q1 to 2001Q2. ${ }^{15}$ The data are taken from International Financial Statistics, Statistics Canada's

\footnotetext{
${ }^{15}$ One could argue that to consider Canada as part of a two-country framework might be inappropriate, because Canada is much smaller than the United States. Recall, however, that our theoretical model allows
} 
database, and the Federal Reserve Bank of St. Louis' database. The gross inflation rate is measured by the change in the CPI in each country. The real exchange rate is constructed by multiplying the nominal exchange rate, defined as the price of one U.S. dollar in terms of Canadian dollars, by the ratio of U.S. CPI to Canadian CPI. The real money stock in each country is measured by M2 divided by the CPI and expressed in per capita terms by dividing it by the civilian population age 16 and over. The real exchange rate and real money stock series are logged and H-P filtered, while the inflation series is logged and demeaned. The inflation differential $\left(\hat{\pi}^{d}\right)$ and the relative real money stock $\left(\hat{m}^{d}\right)$ are constructed by subtracting U.S. inflation and real money stock from their Canadian counterparts.

\section{Empirical Results}

\subsection{Parameter estimates}

From equations (20)-(23), it can readily be seen that the parameters $\varphi, \theta$, and $\xi$ cannot be identified. In addition, it turns out that the elements of the matrices $\mathbf{F}$ and $\mathbf{H}$ that are functions of $\beta, \eta$, and $\kappa$ are such that it is impossible to identify these parameters. Because $\kappa$ is our parameter of interest, and because there is a large consensus regarding the value of the subjective discount factor, on the one hand, and a range of empirical estimates of the interest elasticity of money on the other hand, I choose to fix $\beta$ and $\eta$ and to estimate $\kappa$ along with the parameters $\rho^{\mu}, \rho^{\pi}, \rho^{q}, \rho^{m}, \sigma_{\epsilon_{\mu}}, \sigma_{e_{\pi}}, \sigma_{e_{q}}, \sigma_{e_{m}}$. Based on the arguments made in section 3 , I set $\beta$ to 0.99 and $\eta$ to 10. In section 5.4, however, I perform a sensitivity analysis to assess the robustness of the empirical results to the parameterization of $\eta$.

ML estimates and their corresponding standard errors are reported in Table 1. Standard errors are computed as the square root of the diagonal elements of the inverted Hessian of the (negative) log-likelihood function evaluated at the maximum. At the estimated parameters, the condition for the existence of a unique solution to the model is satisfied. That is, the number of explosive eigenvalues of the matrix $\mathbf{A}=\left[\mathbf{a}_{i j}\right]_{i, j=1,2}$ equals two, the number of non-predetermined variables.

The estimate of the parameter $\kappa$ is equal to 0.0038 . This value is an order of magnitude lower than the estimates found by Galí and Gertler (1999) for the case of a closed-economy Phillips curve. Using GMM and restricting $\beta$ to be equal to unity, Galí and Gertler report

for country size asymmetries through the parameter $n$. The fact that $n$ vanishes once the model is linearized and expressed in terms of country differences makes the empirical model (29)-(31) consistent with any country pair. 
estimates of $\kappa$ of 0.035 and 0.007 , depending on the way the orthogonality conditions are normalized. Although the estimate of $\kappa$ has little informative value per se, it allows us to compute the combinations of $\varphi$ and $\xi$ that lead to the same likelihood function of the model, conditional on the value of $\theta$. This is precisely what is reported in Table 2, where the pairs $(\varphi, \xi)$ are computed assuming that $\theta=11$. Table 2 shows that the estimated value of $\kappa$ implies that the average duration of price contracts has to be about 4.5 years if $\xi=0 .{ }^{16}$ This level of price rigidity is obviously highly implausible and cannot be reconciled with the empirical evidence on price-setting.

Assuming that prices are fixed for one year on average, the duration suggested by Taylor (1999), $\xi$ must be equal to 1.97 for the model to generate the same level of real exchange rate persistence as when the elasticity of demand is constant and prices are fixed for 18 quarters on average. It remains to be seen whether this value of $\xi$ is empirically plausible. Taking "a stab in the dark," Kimball (1995) suggests that $\xi$ equals 4.28, implying that a 1 per cent rise in the firm's market share, which follows from a decline in its relative price, lowers the elasticity of demand from 11 to 8 (so that the desired markup increases from 1.1 to 1.1428). Kimball's parameterization of $\xi$ has been criticized by Chari, Kehoe, and McGrattan (2000b), who argue that such a value of $\xi$ implies an extremely convex demand function. To show this, they take a first-order approximation of the elasticity of demand in the neighbourhood of its steady-state value, $\theta$. This yields (ignoring time and country subscripts)

$$
\theta(y(i) / y) \simeq \theta-[1+\theta-\chi](y(i) / y-1),
$$

where $\chi=-h^{\prime \prime}\left(\psi^{\prime}(1)\right) \psi^{\prime}(1) / h^{\prime}\left(\psi^{\prime}(1)\right)$ is the curvature of the demand function evaluated at the steady state, and $h=\psi^{\prime-1}$. Simple calculation reveals that Kimball's parameterization implies that $\chi=288$. To assess the implied convexity of the demand function, Chari, Kehoe, and McGrattan (2000b) take a second-order Taylor expansion series of the demand function at the steady state. The approximation results in

$$
\psi^{\prime-1}\left(\psi^{\prime}(1) P(i) / P\right) \simeq 1-\theta(P(i) / P-1)+\frac{\chi \theta}{2}(P(i) / P-1)^{2} .
$$

Equation (33) indicates that a value of -288 for the curvature parameter implies that a 2 per cent increase in the relative price leads to an 85 per cent decline in demand compared with a modest 22 per cent reduction that would occur if the elasticity of demand was constant. As Chari, Kehoe, and McGrattan point out, this level of convexity of the demand function is clearly unrealistically high.

\footnotetext{
${ }^{16}$ The average length of price contracts is equal to $1 /(1-\varphi)$.
} 
In light of this result, it is natural to question whether my estimate of $\xi$ results in a plausibly convex demand function. To answer this question, I go through the same steps described above. First, note that my estimated value of $\xi$ means that the elasticity of demand decreases from 11 to 9.37 following a 1 per cent increase in the market share. Using equation (32), it is easy to show that the resulting value of the curvature parameter $\chi$ is -153 . Finally, equation (33) implies that a 2 per cent rise in the relative price yields a 55 per cent decline in demand. The latter value lies halfway between the lowest possible value of 22 per cent (which corresponds to the constant-elasticity-of-demand case) and the value of 85 per cent implied by Kimball's choice of $\xi$. While I do not claim that the convexity of the demand function implied by my estimate of $\xi$ is indisputably plausible, it is certainly not as extreme as that suggested by Kimball's parameterization.

\section{$5.2 \quad$ Fit of the model}

This section assesses the ability of the estimated model to fit the data. In particular, I investigate whether the model can account for the dynamics of the Can $\$ / \mathrm{US} \$$ real exchange rate. Figure 5 plots the actual and predicted series of the model's endogenous variables. It shows that the model tracks the behaviour of the Can\$/US\$ real exchange rate and the relative real money stock remarkably well. The model does not explain as well, however, the movements of the inflation differential between Canada and the United States, as the predicted series looks smoother than the actual one. Going beyond the visual impression that Figure 5 provides, Table 3 reports the moments of the actual and predicted series of the model's variables, showing that the model matches exactly the autocorrelations of the real exchange rate and the relative real money stock. The predicted series of these variables, however, are slightly less volatile than the observed ones. As anticipated, the model is less successful in replicating the volatility of the inflation differential, although it still does a good job matching the historical autocorrelation of this series. Overall, the estimated model seems to fit the data considerably well. More importantly, the model is able to account for the persistence of the Can\$/US\$ real exchange rate. As stated in the previous section, if $\xi=1.97$, then the model can replicate real exchange rate persistence using the assumption that prices are held fixed for four quarters on average. 


\subsection{Variance decomposition}

Given that the fluctuations of the endogenous variables are driven by both structural and non-structural shocks, one might ask how much of these fluctuations is attributed to each type of shock. An assessment of the relative importance of monetary shocks in explaining real exchange rate movements is of primary interest. This issue has recently motivated a new line of research led by Clarida and Galí (1994), who use a structural vector autoregression to compute the variance decomposition of the real exchange rate. Clarida and Galí's identification strategy is based on long-run restrictions that are implied by a stickyprice two-country model inspired by Dornbusch (1976). Using data from Canada, Britain, Germany, and Japan, Clarida and Galí find that demand shocks explain most of the unconditional variance of the change in the real exchange rate. In the case of Canada, only 3 per cent of this variance is due to monetary shocks. Rogoff (1996) views Clarida and Galí's approach as promising. He criticizes their underlying theoretical model, however, stating that it "is based on the somewhat anachronistic Mundell-Fleming-Dornbusch IS-LM framework, rather than a modern sticky price intertemporal model." Because my estimated equations were derived within a dynamic optimizing general-equilibrium framework, Rogoff's criticism does not apply here.

Table 4 shows the variance decomposition of the forecast error of the real exchange rate. It indicates that, at horizons of less than one year, monetary shocks explain slightly more than 40 per cent of real exchange rate variability. This percentage rises steadily as the horizon increases. As the horizon approaches infinity, the conditional variance of the forecast error of a given variable converges to the unconditional variance of that variable. Table 4 shows that roughly 50 per cent of the unconditional variance of the Can $\$ /$ US $\$$ real exchange rate is attributed to monetary shocks. Overall, these results do not corroborate Clarida and Galí's findings.

\subsection{Robustness analysis}

Because, as stated earlier, there is no consensus on the precise magnitude of the interest elasticity of money demand, I check the sensitivity of my results to alternative calibrations of the parameter $\eta$. For this purpose, I estimate the model imposing values of $\eta$ ranging from 1 to 20. Then, from each estimate of $\kappa$, I compute the implied value of $\xi$ assuming that $\varphi=0.75, \theta=11$, and $\beta=0.99$. The implied values of $\xi$ are depicted in Figure 6 . This figure shows that varying $\eta$ in the range that yields plausible values of the interest elasticity 
of money demand has only minor effects on $\xi$. In fact, the implied value of $\xi$ is significantly affected only for values of $\eta$ that are lower than 2 (implying an interest elasticity of money demand above 0.5 ).

The robustness of the results can also be assessed by using an alternative measure of the aggregate price index. So far, the CPI has been used to compute the inflation rate and the real exchange rate, and to deflate the nominal money stock. As an alternative, I use the GDP deflator. Table 5 reports the estimation results based on data constructed using the GDP deflator. Overall, the results are similar to those reported in Table 1. Interestingly, however, the estimate of $\kappa$ is higher than the one obtained using CPI-based data. This implies a lower value of $\xi$ than the one implied by the estimate of $\kappa$ in Table 1, for a given choice of the parameters $\varphi, \theta$, and $\beta$. For example, assuming that $\varphi=0.75, \theta=11$, and $\beta=0.99$, the estimate of $\kappa$ implies that $\xi=1.31$ (compared with 1.97). Thus, in this case, an average length of price contracts of one year can be rationalized with a smaller degree of curvature of the demand function. Therefore, one can conclude that the results are robust and, if anything, better when the GDP deflator is used as an alternative to measure the aggregate price index.

\section{Conclusion}

It is a well-established fact in international finance that real exchange rates are highly volatile and persistent. Standard DGE sticky-price models succeed in replicating the documented volatility, but fail to generate real exchange rates as persistent as in the data. This paper has constructed and estimated a DGE sticky-price model that allows for a timevarying elasticity of demand, which causes a firm's desired markup to vary whenever its relative price changes. Simulation results show that desired markup variations lead to additional nominal rigidity beyond that stemming from the exogenously imposed frictions in the goods market.

The model was estimated by the ML method using Canadian and U.S. data. The estimated model tracks the behaviour of the Can $\$ / \mathrm{US} \$$ real exchange rate remarkably well. In particular, the model is capable of matching exactly the persistence found in the real exchange rate series. More importantly, the model's success is achieved with a plausible duration of price contracts if one allows for a sufficiently convex demand function. Interestingly, I find that the level of convexity required to achieve enough persistence is not as extreme as in Kimball (1995). Yet, the fact that the model underpredicts inflation volatility 
may suggest that the endogenous rigidity that results from desired markup variations is too high. For this reason, one might suspect that the convexity of the demand function is still too high. Nonetheless, this study shows that allowing for desired markup variations in DGE sticky-price models is an important step towards a more complete model that could account for the joint behaviour of inflation and the real exchange rate. 


\section{Appendix A: Derivation of Equations (20)-(23)}

\section{Derivation of equation (20)}

The gross rate of money growth being equal to unity in the steady state, equation (19) is linearized as

$$
\hat{\mu}_{t}=\rho^{\mu} \hat{\mu}_{t-1}+\epsilon_{\mu, t} .
$$

Subtracting from (A.1) its foreign counterpart yields

$$
\hat{\mu}_{t}-\hat{\mu}_{t}^{*}=\rho^{\mu}\left(\hat{\mu}_{t-1}-\hat{\mu}_{t-1}^{*}\right)+\left(\epsilon_{\mu, t}-\epsilon_{\mu, t}^{*}\right),
$$

which is equation (20) in the main text.

\section{Derivation of equation (21)}

Equation (18) is approximated as

$$
\hat{m}_{t}=\hat{m}_{t-1}-\hat{\pi}_{t}+\hat{\mu}_{t} .
$$

Taking the difference between (A.2) and its foreign counterpart results in

$$
\hat{m}_{t}-\hat{m}_{t}^{*}=\left(\hat{m}_{t-1}-\hat{m}_{t-1}^{*}\right)-\left(\hat{\pi}_{t}-\hat{\pi}_{t}^{*}\right)+\left(\hat{\mu}_{t}-\hat{\mu}_{t}^{*}\right)
$$

which is equation (21) in the main text.

\section{Derivation of equation (22)}

Dividing both sides of equation (13) by $P_{t}$ and using the fact that $W_{s} / P_{t}=\left(\Pi_{k=t+1}^{s} \pi_{k}\right) w_{s}$, I obtain

$$
\tilde{p}_{h t}=\frac{E_{t} \sum_{s=t}^{\infty}(\varphi \beta)^{s-t} \Lambda_{t, s} \theta_{s}\left(\tilde{y}_{h s} / y_{s}\right)\left(\Pi_{k=t+1}^{s} \pi_{k}\right) w_{s} \tilde{y}_{h s}}{E_{t} \sum_{s=t}^{\infty}(\varphi \beta)^{s-t} \Lambda_{t, s}\left(\theta_{s}\left(\tilde{y}_{h s} / y_{s}\right)-1\right) \tilde{y}_{h s}},
$$

where $\tilde{p}_{h t}=\tilde{P}_{h t} / P_{t}$. This equation can be approximated as

$$
\begin{aligned}
\widehat{\tilde{p}}_{h t} & =(1-\varphi \beta) E_{t} \sum_{s=t}^{\infty}(\varphi \beta)^{s-t}\left(\hat{w}_{s}+\sum_{k=t+1}^{s} \hat{\pi}_{k}+\frac{\hat{\theta}_{s}}{\theta-1}\right) \\
& =(1-\varphi \beta) E_{t} \sum_{s=t}^{\infty}(\varphi \beta)^{s-t}\left(\hat{w}_{s}+\sum_{k=t+1}^{s} \hat{\pi}_{k}-\hat{\nu}_{s}\right) \\
& =(1-\varphi \beta) E_{t} \sum_{s=t}^{\infty}(\varphi \beta)^{s-t}\left(\hat{w}_{s}+\sum_{k=t+1}^{s} \hat{\pi}_{k}-\theta \xi \widehat{\tilde{p}}_{h t}\right) \\
& =\frac{1-\varphi \beta}{1+\theta \xi} E_{t} \sum_{s=t}^{\infty}(\varphi \beta)^{s-t}\left(\hat{w}_{s}+\sum_{k=t+1}^{s} \hat{\pi}_{k}\right),
\end{aligned}
$$


which can be rewritten in the following recursive form

$$
\widehat{\tilde{p}}_{h t}-\varphi \beta E_{t} \widehat{\tilde{p}}_{h t+1}=\frac{1-\varphi \beta}{1+\theta \xi} \hat{w}_{t}+\frac{\varphi \beta}{1+\theta \xi} E_{t} \hat{\pi}_{t+1} .
$$

Similarly, dividing both sides of equation (14) by $P_{t}^{*}$ and using the fact that $e_{s} P_{t}^{*} / P_{t}=$ $\left(\Pi_{k=t+1}^{s} \pi_{k}\right)\left(\Pi_{k=t+1}^{s} \pi_{k}^{*}\right)^{-1} q_{s}$, yields

$$
\tilde{p}_{h t}^{*}=\frac{E_{t} \sum_{s=t}^{\infty}(\varphi \beta)^{s-t} \Lambda_{t, s} \theta_{s}\left(\tilde{y}_{h s}^{*} / y_{s}^{*}\right)\left(\Pi_{k=t+1}^{s} \pi_{k}\right) w_{s} \tilde{y}_{h s}^{*}}{E_{t} \sum_{s=t}^{\infty}(\varphi \beta)^{s-t} \Lambda_{t, s}\left(\theta_{s}\left(\tilde{y}_{h s}^{*} / y_{s}^{*}\right)-1\right)\left(\Pi_{k=t+1}^{s} \pi_{k}\right)\left(\Pi_{k=t+1}^{s} \pi_{k}^{*}\right)^{-1} q_{s} \tilde{y}_{h s}^{*}},
$$

where $\tilde{p}_{h t}^{*}=\tilde{P}_{h t}^{*} / P_{t}^{*}$. Following the same steps involved in obtaining equation (A.4), it is easy to show that the approximation of equation (A.5) can be written as

$$
\widehat{\tilde{p}}_{h t}^{*}-\varphi \beta E_{t} \widehat{\tilde{p}}_{h t+1}^{*}=\frac{1-\varphi \beta}{1+\theta \xi}\left(\hat{w}_{t}-\hat{q}_{t}\right)+\frac{\varphi \beta}{1+\theta \xi} E_{t} \hat{\pi}_{t+1}^{*} .
$$

By analogy to (A.3) and (A.5), the pricing decisions by the foreign monopolistic firm are approximated by

$$
\widehat{\tilde{p}}_{f t}-\varphi \beta E_{t} \widehat{\tilde{p}}_{f t+1}=\frac{1-\varphi \beta}{1+\theta \xi}\left(\hat{w}_{t}^{*}+\hat{q}_{t}\right)+\frac{\varphi \beta}{1+\theta \xi} E_{t} \hat{\pi}_{t+1},
$$

and

$$
\widehat{\tilde{p}}_{f t}^{*}-\varphi \beta E_{t} \widehat{\tilde{p}}_{f t+1}^{*}=\frac{1-\varphi \beta}{1+\theta \xi} \hat{w}_{t}^{*}+\frac{\varphi \beta}{1+\theta \xi} E_{t} \hat{\pi}_{t+1}^{*},
$$

where $\tilde{p}_{f t}=\tilde{P}_{f t} / P_{t}$ and $\tilde{p}_{f t}^{*}=\tilde{P}_{f t}^{*} / P_{t}^{*}$.

Using equations (12), (15), and (16), I obtain

$$
P_{t}=(1-\varphi) \sum_{s=-\infty}^{t} \varphi^{t-s}\left[n \tilde{P}_{h s} \psi^{\prime-1}\left(\psi^{\prime}(1) \tilde{P}_{h s} / P_{t}\right)+(1-n) \tilde{P}_{f s} \psi^{\prime-1}\left(\psi^{\prime}(1) \tilde{P}_{f s} / P_{t}\right)\right] .
$$

Dividing both sides of equation (A.9) by $P_{t}$ results in

$$
\begin{aligned}
1= & (1-\varphi) \sum_{s=-\infty}^{t} \varphi^{t-s}\left[n \tilde{p}_{h s}\left(\Pi_{k=s+1}^{t} \pi_{k}\right)^{-1} \psi^{\prime-1}\left(\psi^{\prime}(1) \tilde{p}_{h s}\left(\Pi_{k=s+1}^{t} \pi_{k}\right)^{-1}\right)\right. \\
& \left.+(1-n) \tilde{p}_{f s}\left(\Pi_{k=s+1}^{t} \pi_{k}\right)^{-1} \psi^{\prime-1}\left(\psi^{\prime}(1) \tilde{p}_{f s}\left(\Pi_{k=s+1}^{t} \pi_{k}\right)^{-1}\right)\right]
\end{aligned}
$$

The linearization of this equation yields

$$
0=(1-\varphi) \sum_{s=-\infty}^{t} \varphi^{t-s}\left[n\left(\widehat{\tilde{p}}_{h s}-\sum_{k=s+1}^{t} \hat{\pi}_{k}\right)+(1-n)\left(\widehat{\tilde{p}}_{f s}-\sum_{k=s+1}^{t} \hat{\pi}_{k}\right)\right],
$$


or

$$
\hat{\pi}_{t}=(1-\varphi) \sum_{s=-\infty}^{t} \varphi^{t-s-1}\left[n\left(\widehat{\tilde{p}}_{h s}-\sum_{k=s+1}^{t-1} \hat{\pi}_{k}\right)+(1-n)\left(\widehat{\tilde{p}}_{f s}-\sum_{k=s+1}^{t-1} \hat{\pi}_{k}\right)\right] .
$$

Subtracting $\varphi \hat{\pi}_{t}$ from both sides of this equation gives

$$
\hat{\pi}_{t}=\frac{1-\varphi}{\varphi}\left[n \widehat{\tilde{p}}_{h t}+(1-n) \widehat{\tilde{p}}_{f t}\right] .
$$

The foreign counterpart of equation (A.10) is

$$
\hat{\pi}_{t}^{*}=\frac{1-\varphi}{\varphi}\left[n \widehat{\tilde{p}}_{h t}^{*}+(1-n) \widehat{\tilde{p}}_{f t}^{*}\right] .
$$

Substituting (A.4) and (A.7) into (A.10) and rearranging, I obtain

$$
E_{t} \hat{\pi}_{t+1}=\frac{1}{\beta} \hat{\pi}_{t}-\frac{(1-\varphi)(1-\varphi \beta)}{\varphi \beta(1+\theta \xi)}\left[n \hat{w}_{t}+(1-n)\left(\hat{w}_{t}^{*}+\hat{q}_{t}\right)\right] .
$$

Similarly, equation (A.11), with (A.6) and (A.8) substituted in for $\widehat{\widetilde{p}}_{h t}^{*}$ and $\widehat{\widetilde{p}}_{f t}^{*}$, becomes

$$
E_{t} \hat{\pi}_{t+1}^{*}=\frac{1}{\beta} \hat{\pi}_{t}^{*}-\frac{(1-\varphi)(1-\varphi \beta)}{\varphi \beta(1+\theta \xi)}\left[n\left(\hat{w}_{t}-\hat{q}_{t}\right)+(1-n) \hat{w}_{t}^{*}\right] .
$$

Finally, subtracting (A.13) from (A.12) yields

$$
E_{t}\left(\hat{\pi}_{t+1}-\hat{\pi}_{t+1}^{*}\right)=\frac{1}{\beta}\left(\hat{\pi}_{t}-\hat{\pi}_{t}^{*}\right)-\frac{(1-\varphi)(1-\varphi \beta)}{\varphi \beta(1+\theta \xi)} \hat{q}_{t},
$$

which is equation (22) in the main text.

\section{Derivation of equation (23)}

Linearizing the first-order conditions (6) and (7) yields, respectively,

$$
\eta \hat{m}_{t}=\frac{\beta}{1-\beta}\left(E_{t} \hat{\lambda}_{t+1}-E_{t} \hat{\pi}_{t+1}\right)-\frac{1}{1-\beta} \hat{\lambda}_{t}
$$

and

$$
\eta \hat{m}_{t}^{*}=\frac{\beta}{1-\beta}\left(E \hat{\lambda}_{t+1}+E_{t} \hat{q}_{t+1}-E_{t} \hat{\pi}_{t+1}^{*}\right)-\frac{1}{1-\beta}\left(\hat{\lambda}_{t}+\hat{q}_{t}\right) .
$$

Subtracting (A.14) from (A.15) and rearranging, I obtain

$$
E_{t} \hat{q}_{t+1}=\frac{1}{\beta} \hat{q}_{t}-E_{t}\left(\hat{\pi}_{t+1}-\hat{\pi}_{t+1}^{*}\right)-\frac{\eta(1-\beta)}{\beta}\left(\hat{m}_{t}-\hat{m}_{t}^{*}\right),
$$

which is equation (23) in the main text. 


\section{References}

[1] Altug, S. (1989), "Time-to-Build and Aggregate Fluctuations: Some New Evidence," International Economic Review 30, 889-920.

[2] Ball, L. and D. Romer (1990), "Real Rigidities and the Non-Neutrality of Money", Review of Economic Studies 57, 183-203.

[3] Basu, S and J. Fernald (1994), "Constant Returns and Small Markups in US Manufacturing," International Finance Discussion Paper 483.

[4] Bergin, P. (2002), "Putting the New Open Economy Macroeconomics to a Test", Journal of International Economics, forthcoming.

[5] Bergin, P. and R. Feenstra (2000), "Staggered Price Setting, Translog Preferences, and Endogenous Persistence", Journal of Monetary Economics 45, 657-680.

[6] Bergin, P. and R. Feenstra (2001), "Pricing to Market, Staggered Contracts and Real Exchange Rate Persistence", Journal of International Economics 54, 333-359.

[7] Betts, C. and M. Devereux (1996), "The Exchange Rate in a Model of Pricing-toMarket", European Economic Review 40, 1007-1021.

[8] — (2000), "Exchange rate Dynamics in a Model of Pricing-to-Market", Journal of International Economics 50, 215-244.

[9] Blanchard, O. J. and Kahn, C. M. (1980), "The Solution of Linear Difference Models Under Rational Expectations," Econometrica 48, 1305-1311.

[10] Bouakez, H. (2002), "Habit Formation, Pricing-to-Market and Real Exchange Rate Dynamics", mimeo, Université de Montréal, May.

[11] Calvo, G. (1983), "Staggered Prices in a Utility Maximization Framework", Journal of Monetary Economics 12, 983-998.

[12] Chari, V., P. Kehoe, and E. McGrattan (2000a), "Can Sticky Price Models Generate Volatile and Persistent Real Exchange Rates ?", Federal Reserve Bank of Minneapolis Research Department Staff Report 277. 
[13] Chari, V., P. Kehoe, and E. McGrattan (2000b), "Sticky Price Models of the Business Cycle: Can the Contract Multiplier Solve the Persistence Problem," Econometrica, 68, 1151-1179.

[14] Christiano, L. J., M. Eichenbaum and C. L. Evans (2001), "Nominal Rigidities and the Dynamic Effects of a Shock to Monetary Policy", NBER Working Paper 8403.

[15] Clarida, R. and J. Galí (1994), "Sources of Real Exchange Rate Fluctuations: How Important Are Nominal Shocks ?", NBER Working Paper 4658.

[16] Dornbusch, R. (1976), "Expectations and Exchange Rate Dynamics", Journal of Political Economy 84, 1161-1177.

[17] Engel, C. (1993), "Real Exchange Rate and Relative Prices: An Empirical Investigation", Journal of Monetary Economics 32, 35-50.

[18] Engel, C. and J. Rogers (1996), "How Wide is the Border", American Economic Review $86,1112-1125$.

[19] Galí, J. and M. Gertler (1999), "Inflation Dynamics: A Structural Econometric Analysis" Journal of Monetary Economics 44, 195-222.

[20] Galí, J. and T. Monacelli (2002), "Optimal Monetary Policy and Exchange Rate Volatility in a Small Open Economy", Working Paper, March.

[21] Ireland, P. (1999), "A Method of Taking Models to the Data", mimeo, Boston College, April.

[22] (2001), "Sticky-Price Models of the Business Cycle: Specification and Stability", Journal of Monetary Economics 47, 3-18.

[23] Kimball, M. (1995), "The Quantitative Analytics of the Basic Neomonetarist Model", Journal of Money, Credit and Banking 27, 1241-1277.

[24] Knetter, M. (1989), "Price Discrimination by U.S. and German Exporters", American Economic Review 79, 198-210.

[25] Knetter, M. (1993), "International Comparison of Pricing-to-Market Behavior", American Economic Review 83, 473-486. 
[26] Kollmann, R. (2001), "The Exchange Rate in a Dynamic Optimizing Current Account Model with Nominal Rigidities: A Quantitative Investigation", Journal of International Economics 55, 243-262.

[27] Mankiw, N. G. and L. H. Summers. (1986), "Money Demand and the Effects of Fiscal Policies", Journal of Money, Credit and Banking 18, 415-429.

[28] McGrattan, E. R. (1994), "The Macroeconomic Effects of Distortionary Taxation," Journal of Monetary Economics 33, 573-601.

[29] McGrattan, E. R., R. Rogerson and R. Wright (1997), "An Equilibrium Model of the Business Cycle with Household Production and Fiscal Policy," International Economic Review 38, 267-290.

[30] Obstfeld, M. and K. Rogoff (1995), "Exchange Rate Dynamics Redux", Journal of Political Economy 103, 624-660.

[31] Razin, A. and C. Yuen (2001), "The New Keynesian Phillips Curve: Closed Economy vs. Open Economy", NBER Working Paper 8313.

[32] Rogoff, K (1996), "The Purchasing Power Parity Puzzle", Journal of Economic Literature 34, 647-688.

[33] Rotemberg, J. J. and M. Woodford (1999), "The Cyclical Behavior of Prices and Costs", NBER Working Paper 6909.

[34] Stiglitz, J. E. (1979), "Equilibrium in Product Markets with Imperfect Information", American Economic Review 69, 339-345.

[35] Taylor, J. B. (1999), "Staggered Prices and Wage Setting in Macroeconomics," in J. B. Taylor and M. Woodford, eds., Handbook of Macroeconomics, Amsterdam: NorthHolland.

[36] Woglom, G. (1982), "Underemployment Equilibrium with Rational Expectations", Quarterly Journal of Economics 97, 89-107.

[37] Woodford, M. (1996), "Control of the Public Debt: A Requirement for Price Stability", NBER Working Paper 5684. 


\section{Table 1. Maximum-Likelihood Estimates}

\begin{tabular}{ccc}
\hline \hline Parameter & Estimate & Standard error \\
\hline$\kappa$ & 0.0038 & 0.0040 \\
$\rho^{\mu}$ & 0.2596 & 0.2406 \\
$\rho^{\pi}$ & 0.4849 & 0.0886 \\
$\rho^{q}$ & 0.8921 & 0.0536 \\
$\rho^{m}$ & 0.9362 & 0.0323 \\
$\sigma_{\epsilon_{\mu}}$ & 0.0041 & 0.0014 \\
$\sigma_{e_{\pi}}$ & 0.0051 & 0.0003 \\
$\sigma_{e_{q}}$ & 0.0119 & 0.0021 \\
$\sigma_{e_{m}}$ & 0.0109 & 0.0008 \\
\hline \hline
\end{tabular}

Notes: The restrictions imposed on the parameters are $\kappa, \sigma_{\epsilon_{\mu}}, \sigma_{e_{\pi}}, \sigma_{e_{q}}, \sigma_{e_{m}} \in(0, \infty)$ and $\rho^{\mu}, \rho^{\pi}, \rho^{q}, \rho^{m} \in(-1,1)$. Standard errors are the square root of the diagonal elements of the inverted Hessian of the (negative) log-likelihood function evaluated at the estimates. 
Table 2. Combinations of $\varphi$ and $\xi$ that Yield the Same Value of the Likelihood Function

\begin{tabular}{ccc}
\hline \hline$\varphi$ & $1 /(1-\varphi)$ & $\xi$ \\
\hline 0.1 & 1.11 & 195.07 \\
0.2 & 1.25 & 77.12 \\
0.3 & 1.43 & 39.39 \\
0.4 & 1.67 & 21.71 \\
0.5 & 2 & 12.06 \\
0.6 & 2.5 & 6.42 \\
0.7 & 3.33 & 3.07 \\
$\mathbf{0 . 7 5}$ & $\mathbf{4}$ & $\mathbf{1 . 9 7}$ \\
0.8 & 5 & 1.16 \\
0.9 & 10 & 0.20 \\
$\mathbf{0 . 9 4 4 8}$ & $\mathbf{1 8 . 1 1}$ & $\mathbf{0}$ \\
\hline \hline
\end{tabular}

Notes: $1 /(1-\varphi)$ is the average length of price contracts in quarters. For each value of $\varphi$, the implied value of $\xi$ is computed assuming that $\beta=0.99$ and $\theta=11$. 
Table 3. Moments of Actual and Predicted Series of the Model's Variables

\begin{tabular}{lccccc}
\hline \hline \multirow{2}{*}{ Variable } & \multicolumn{2}{c}{ Autocorrelation } & & \multicolumn{2}{c}{ Standard deviation (\%) } \\
\cline { 2 - 3 } \cline { 5 - 6 } & Actual & Predicted & & Actual & Predicted \\
\hline Inflation differential & 0.49 & 0.52 & & 0.59 & 0.29 \\
Real exchange rate & 0.86 & 0.86 & & 3.18 & 2.88 \\
Relative real money stock & 0.92 & 0.92 & & 3.39 & 3.15 \\
\hline \hline
\end{tabular}


Table 4. Variance Decomposition of the Real Exchange Rate

\begin{tabular}{cc}
\hline \hline Horizon & $\begin{array}{c}\text { Fraction of variance due to } \\
\text { monetary shocks }\end{array}$ \\
\hline 1 & 0.4167 \\
2 & 0.4268 \\
3 & 0.4348 \\
4 & 0.4417 \\
8 & 0.4626 \\
12 & 0.4723 \\
24 & 0.4932 \\
$\infty$ & 0.4970 \\
\hline \hline
\end{tabular}


Table 5. Maximum-Likelihood Estimates using the GDP Deflator as a Measure of the Aggregate Price Index

\begin{tabular}{ccc}
\hline \hline Parameter & Estimate & Standard error \\
\hline$\kappa$ & 0.0056 & 0.0049 \\
$\rho^{\mu}$ & 0.1766 & 0.1843 \\
$\rho^{\pi}$ & 0.1681 & 0.1149 \\
$\rho^{q}$ & 0.9006 & 0.0461 \\
$\rho^{m}$ & 0.9299 & 0.0349 \\
$\sigma_{\epsilon_{\mu}}$ & 0.0049 & 0.0012 \\
$\sigma_{e_{\pi}}$ & 0.0048 & 0.0003 \\
$\sigma_{e_{q}}$ & 0.0139 & 0.0016 \\
$\sigma_{e_{m}}$ & 0.0089 & 0.0008 \\
\hline \hline
\end{tabular}



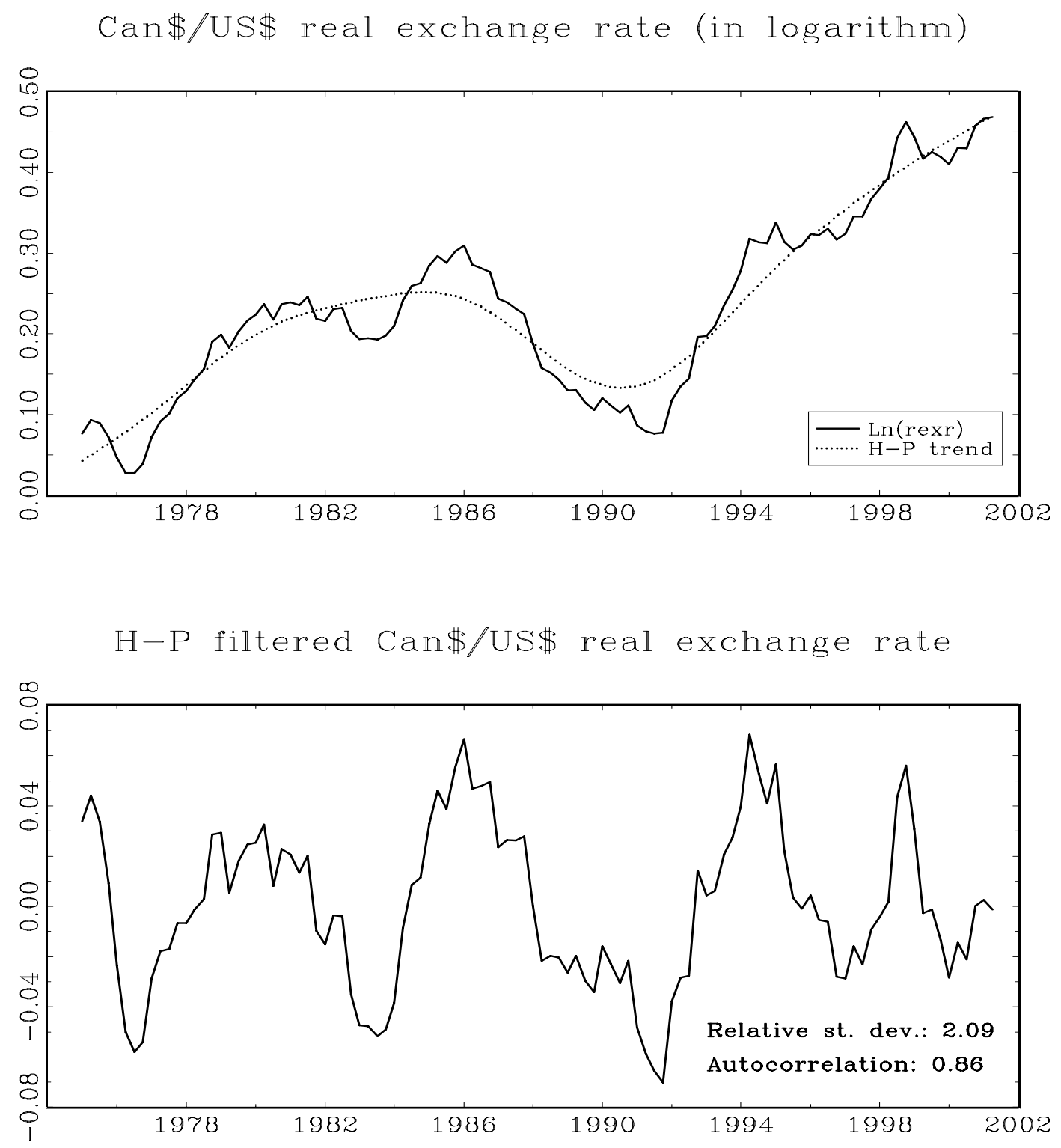

Figure 1: Can $\$ / \mathrm{US} \$$ real exchange rate properties 
Inflation differential

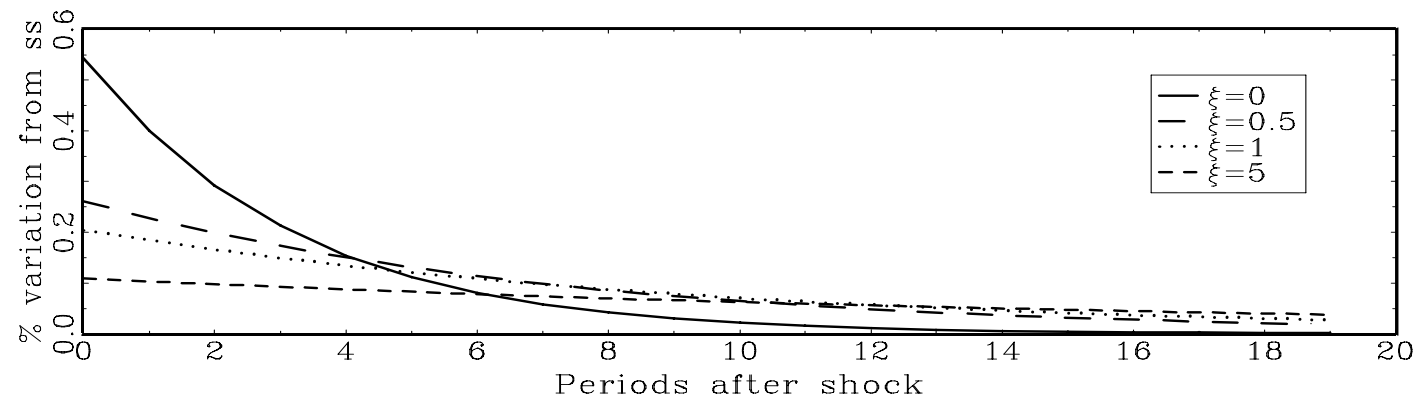

Real exchange rate

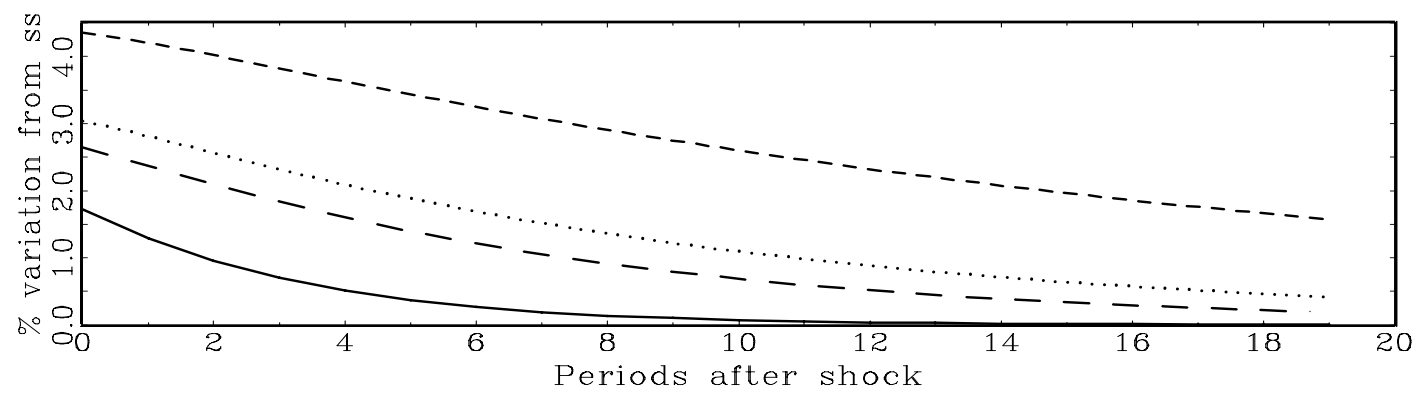

Relative real money stock

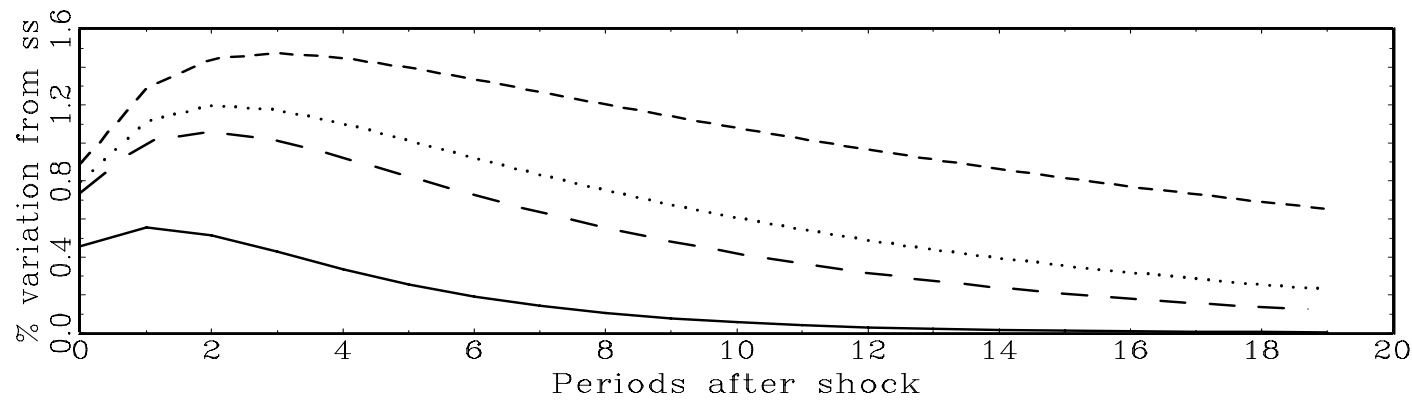

Figure 2: Impulse responses to a 1 per cent money-growth shock for different values of $\xi$ 


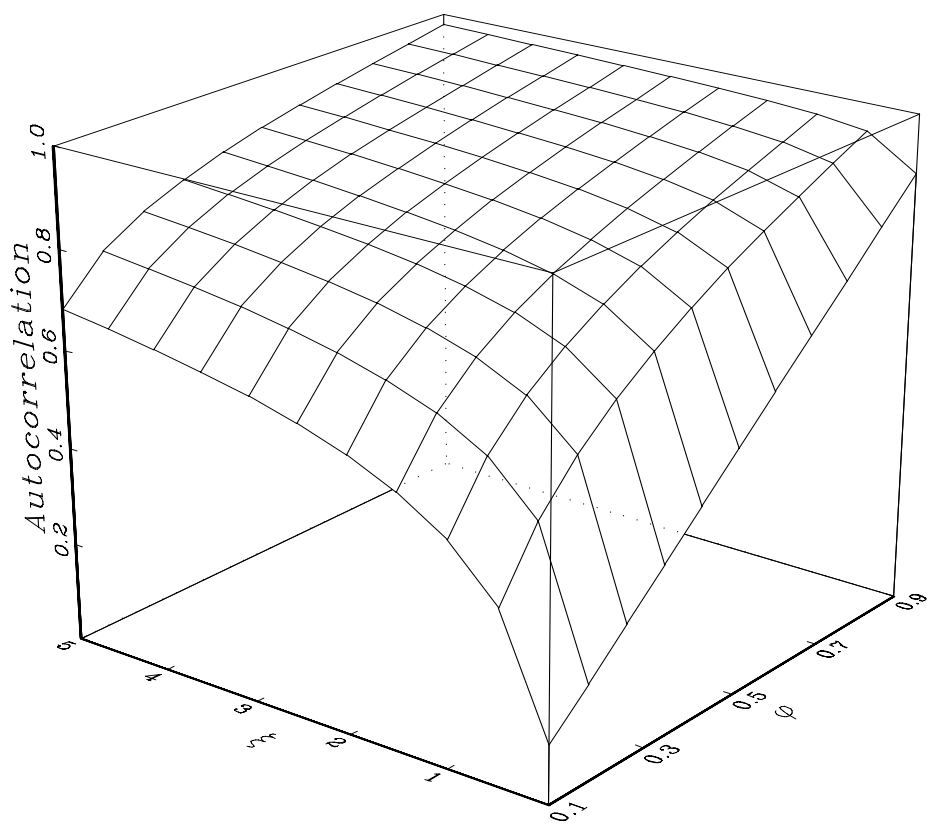

Figure 3: Real exchange rate persistence as a function of $\varphi$ and $\xi$ 




Figure 4: Iso-persistence curves 
Inflation differential

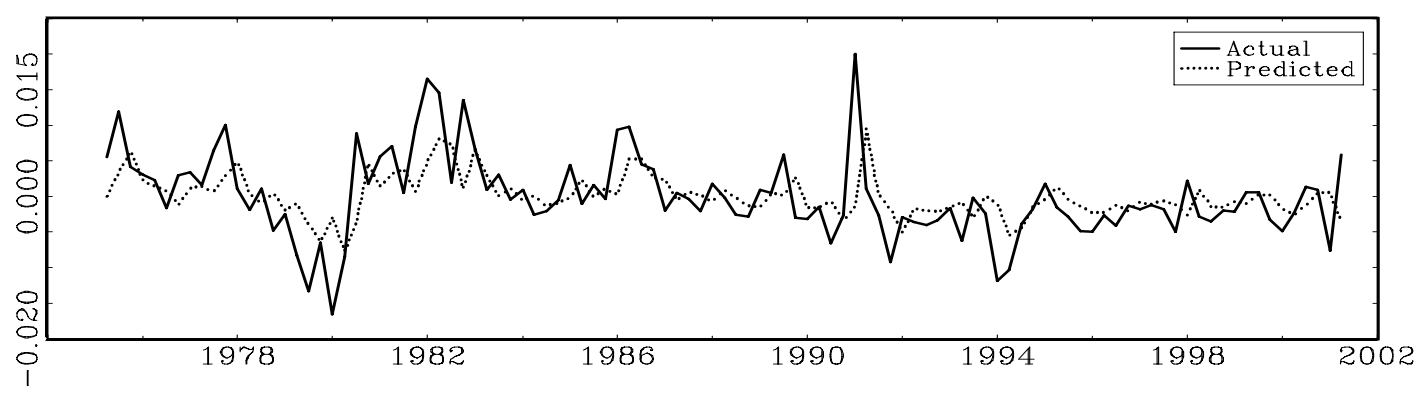

Real exchange rate

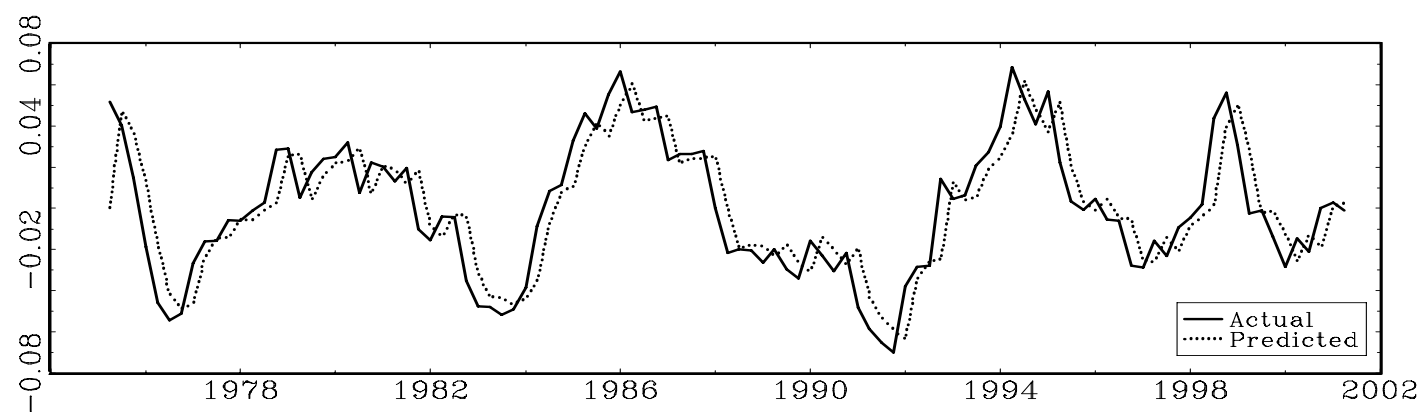

Relative real money stock

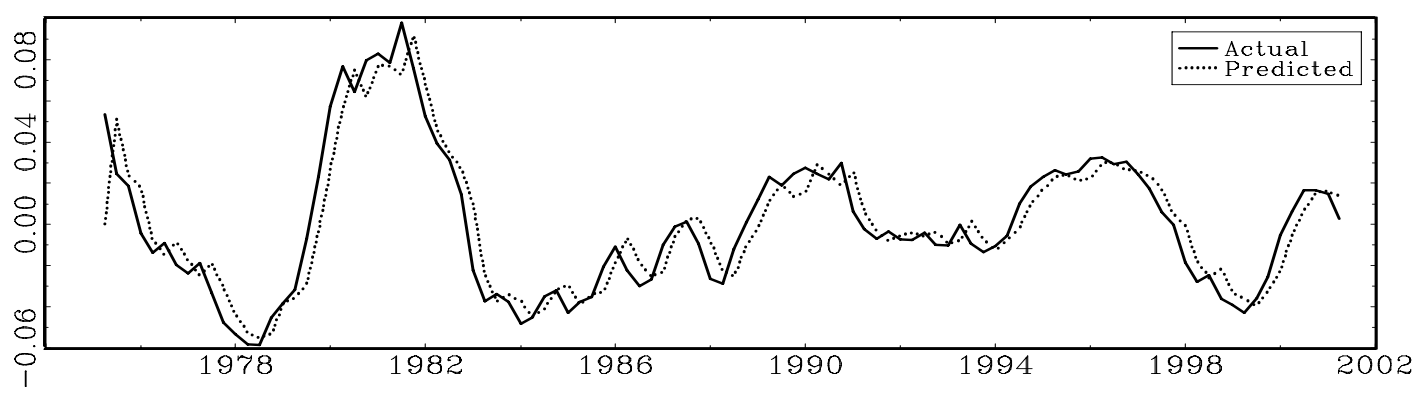

Figure 5: Actual vs. predicted values of endogenous variables 


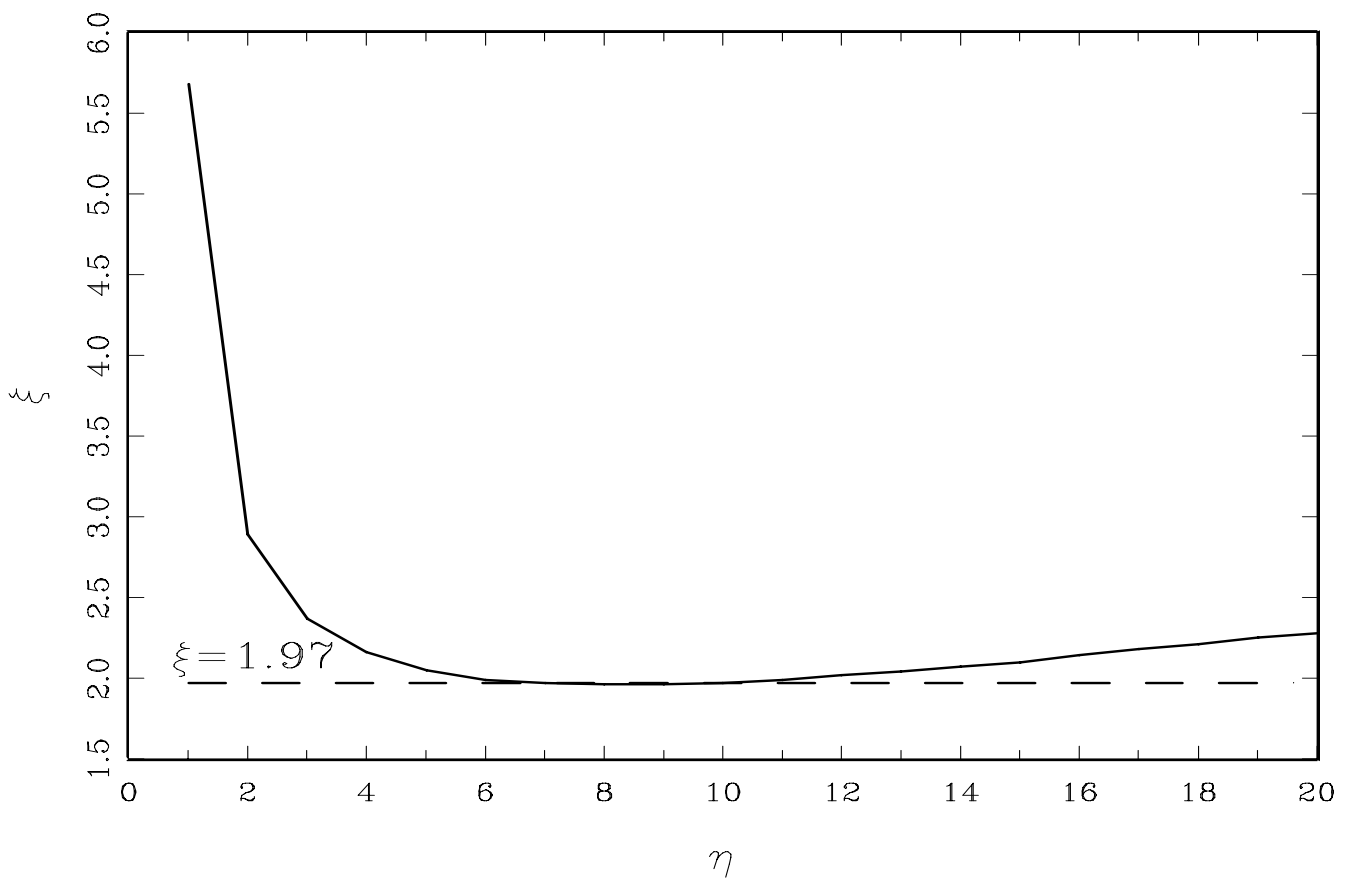

Figure 6: Sensitivity of the implied value of $\xi$ to the parameter $\eta$ $(\varphi=0.75, \theta=11$, and $\beta=0.99)$ 